We wish to acknowledge Figs. 2 and 4 to the National Cancer Institute, Washington, D.C. We are grateful to Miss Ella Wright for much secretarial and other assistance.

Reprints should be ordered from Mr. D. P. Burkitt, Medical Research Council, 172 Tottenham Court Road, London W.1.

\section{REFERENCES}

Burchenal, J. H. (1967). Cancer Res., 26, 2393.

Burkitt, D. P. (1967a). Possible Relationships between the African

Lymphoma and Acute Leukaemia. London.
Burkitt, D. P. (1967b). The Treatment of Burkitt Tumour. UICC Monograph Series, No. 8, edited by J. H. Burchenal and D. P. Monograph Series, No. 8,

Burkitt, D., Hutt, M. S. R., and Wright, D. H. (1965). Cancer (Philad.), 18, 399.
Burkitt, D. P., and Kyalwazi, S. K. (1967). Brit. F. Cancer, 21, 14.

Klein, G., Klein, E., and Clifford, P. (1968). Search for host defences in Burkitt lymphoma: Membrane imm

McAdam, I. W. J. (1968). In W. W. Davey's Companion to Surgery in Africa, p. 93. Edinburgh and London.

Morrow, R. H., Pike, M. C., and Kisuule, A. (1967). Brit. med. 7., 4, 323.

Ngu, V. A. (1967). The Treatment of Burkitt Tumour. UICC Monograph Series, No. 8, edited by J. H. Burchenal and D. P. Burkitt, p. 204. Heidelberg.

Osunkoya, B. O. (1967). The Treatment of Burkitt Tumour, UICC Monograph Series, No. 8, edited by J. H. Burchenal and D. P. Burkitt, p. 233. Heidelberg.

Pike, M. C. (1966). Lancet, 2, 856.

Pike, M. C., Williams, E. H., and Wright, B. (1967). Brit. med. f., 2, 395.

\title{
Sleep and Barbiturates: some Experiments and Observations*
}

\author{
J. I. EVANS, † M.B., CH.B., D.P.M. ; S. A. LEWIS, ‡ B.SC. ; I. A. M. GIBB,§ M.B., CH.B., D.P.M. \\ MARY CHEETHAM, $\|$ M.B., CH.B., D.A.
}

Brit. med. F., 1968, 4, 291-293

\begin{abstract}
Cummary : To determine the effect of barbiturates on $\checkmark$ sleep two subjects, after a control period, received 200 mg. of sodium amylobarbitone for 26 nights. All night sleep records taken during this period showed that the barbiturate shortened the delay to sleep, increased the total sleep period, lengthened the delay to rapid eye movement (R.E.M.) sleep, and depressed R.E.M. sleep. After five nights R.E.M. sleep returned to baseline values -that is, showed tolerance. On stopping the drug withdrawal phenomena were seen, even to this small dose of the drug.
\end{abstract}

In a second experiment a subject dependent on $600 \mathrm{mg}$. of Tuinal was found to have low normal R.E.M. sleep while on drugs. On withdrawal, delay to sleep increased and total sleep time fell. R.E.M. sleep was doubled and the delay to R.E.M. became abnormally short.

These findings suggest that hypnotics allow sleep to be " borrowed," and that patients should be supported while they are being withdrawn.

\section{Introduction}

In the past decade drugs have become the focus of attention of many groups in society. Doctors have become more aware of their side-effects, prolonged actions, effects on foetal development, and the possibility of addiction and overdose. Society has become anxious over the questions of abuse and addiction, and these anxieties have produced a number of standing committees in an effort to control this complex problem.

The need for such control is apparent even when the quantity of drugs consumed for therapeutic reasons is appreciated. Ministry of Health (1964) statistics show that hypnotics, analgesics, and tranquillizers constitute $22.6 \%$ of all prescriptions. Of this group barbiturates are the largest contributors, making up $8.1 \%$ of all prescriptions, and the amount increases annually. Other indices confirm the increasing use and abuse of these drugs. Overdosage by hypnotics has increased

- From the Sleep Laboratory, University Department of Psychiatry, (Royal Edinburgh Hospital), Edinburgh 10 .

t Lecturer, University Department of Psychiatry, Edinburgh.

₹ Medical Research Council Scholar, University Department of Psychiatry, Edinburgh.

S Late Registrar, Royal Edinburgh Hospital.

[I Late Senior House Officer, Royal Edinburgh Hospital. steadily as a means of attempting suicide (Kessel, 1965), and delirium due to abrupt withdrawal is a frequent hazard (James, 1963).

Many doctors were taught that whatever else they could not do for their patients they could at least provide sleep. This expectation seems to have passed on to the patients, as doctors often complain that they feel under pressure to prescribe hypnotics.

In the past decade knowledge about sleep has also greatly increased. It has been found to consist of two regularly alternating states (Aserinsky and Kleitman, 1953, 1955), which differ drastically in many physiological criteria.

At the beginning of the night the normal subject enters a cycle of sleep which is characterized by slow waves and spindling activity in the E.E.G., slow rolling/absent eye movements, the presence of muscle activity, and regularity of pulse rate, blood pressure, and respiration. After about an hour of this slow wave or "orthodox sleep" there is an abrupt change. Spindles disappear from the E.E.G., muscle tone drops precipitately in the submental region (Berger, 1961), the E.E.G. becomes low-voltage, and runs of sharp waves appear-the "saw tooth" frontal activity which is followed by bursts of jerking synchronous eye movements (Dement and Kleitman, 1957). Respiration and pulse rate become irregular and blood pressure is variable (Snyder et al., 1963, 1964). After 10 to 20 minutes the eye movements disappear, often after a body movement, and spindles reappear as another cycle of slow wave sleep begins. This second type of sleep has been called " paradoxical " or rapid eye movement (R.E.M.) sleep.

In the normal night five or six cycles of orthodox sleep with an equivalent number of periods of paradoxical sleep occur. Paradoxical (R.E.M.) sleep usually occupies about $24 \%$ of the total sleep. Normally, orthodox sleep takes precedence over R.E.M. sleep, and the first R.E.M. period of the night does not occur until after at least 45 minutes of orthodox sleep (Rechtschaffen and Verdone, 1964 ; Oswald and Priest, 1965).

Mental activity differs in these two types of sleep. In orthodox sleep mental activity is variable, often fragmentary, and more reality-orientated. During R.E.M. sleep disorientation in time and place is common and dreams are reponted (Aserinsky and Kleitman, 1953 ; Goodenough et al., 1959 ; Monroe et al., 1965). To determine the effect of drugs on 
sleep we have conducted a number of electroencephalographic studies in volunteers.

\section{Method}

During these investigations subjects reported to the laboratory at 22.00 hours, and electrodes were attached with adhesives to $\mathrm{Fz} \mathrm{Cz} \mathrm{Pz}$ positions of the $10 / 20$ system to collect the E.E.G. ; to frontal and outer canthi positions to monitor eye movements; and over the belly of the submental muscles to record muscle tone. Bipolar montages were employed and the electroencephalograph was run continuously from 23.30 to 8.00 hours.

Subjects were instructed to keep regular hours of sleep throughout the total experimental period and refrain from alcohol or drugs other than those prescribed in the experiment.

The record-almost a quarter of a mile $(400 \mathrm{~m}$.) of paperwas analysed according to the types of sleep. Normal indices were (i) the total sleep time (T.S.T.) from first spindle to final arousal minus any intervening period of wakefulness ; (ii) total R.E.M. sleep and percentage R.E.M. sleep-the sum of all R.E.M. activity from first eye movements to last R.E.M. minus any intervening period of spindling activity which can intrude into R.E.M. sleep ; (iii) the delay to sleep (iv)-the interval in minutes from the start of recording from "lights out" to first spindles ; and (iv) delay to R.E.M. (D)-the interval from first spindles to first R.E.M.

\section{Experiment 1}

Two female subjects were used as their own controls. Over a period of six weeks seven baseline recordings were made at irregular intervals. The first record was discaráed, as is accepted practice, since the results are often low owing to a "first night" effect (Mendels and Hawkins, 1967). Subjects then received $200 \mathrm{mg}$. of sodium amylobarbitone at 23.00 hours each night for 26 nights. Recordings were taken at intervals over the next two weeks until all variables were within the normal range. Altogether 27 nights were recorded over a period of almost three months (see Fig. 2).

\section{Results}

The immediate effect of the drug was to decrease the delay to sleep and prolong the T.S.T. (Fig. 1). R.E.M. sleep was depressed (Fig. 2) and orthodox sleep was enhanced. R.E.M. sleep continued below the baseline for five nights; then tolerance occurred and R.E.M. values rose to baseline or a little above it. During this period of tolerance the drug still promoted

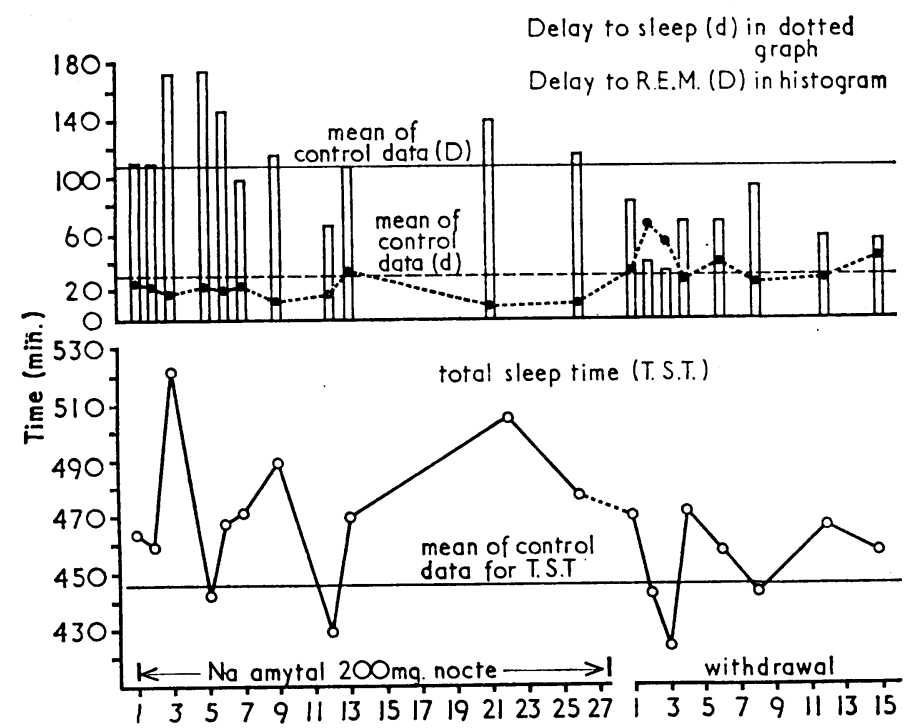

FIG. 1.-Effects of sodium amylobarbitone $200 \mathrm{mg}$. nocte on sleep of two female subjects. and enhanced orthodox sleep so that T.S.T. remained raised. The delay to the first R.E.M. period was increased by the drug. However, at nights 12-14 T.S.T. fell, the delay to sleep increased slightly, and the amount of R.E.M. activity rose: at night 12 the delay to R.E.M. period was below the baseline value.

When the barbiturate was stopped, T.S.T. fell abruptly for the first two nights and the delay to sleep was much prolonged. Delay to R.E.M. became abnormally short (less than 45 minutes) during this period, and R.E.M. sleep was increased-up to $31 \%$ of the night. R.E.M. sleep subsided towards baseline in a fluctuant manner over the next fortnight.

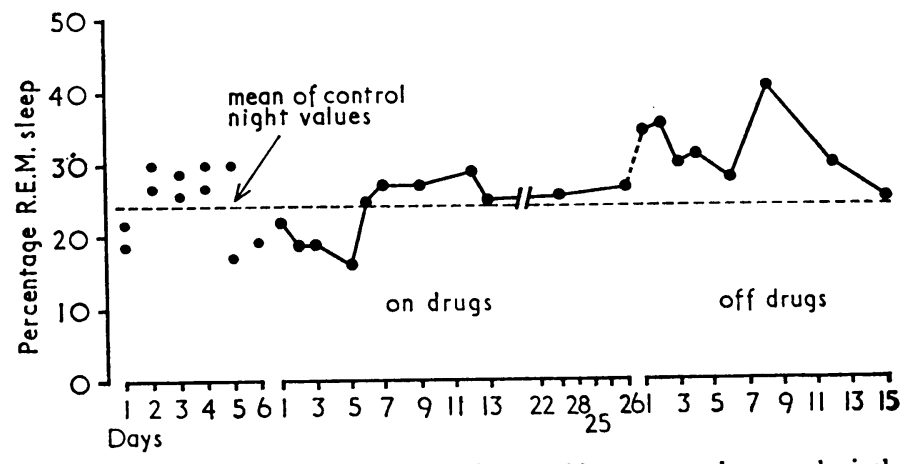

Fig. 2.-Effect of sodium amylobarbitone $200 \mathrm{mg}$. on the paradoxical sleep of two subjects.

\section{Experiment 2}

This subject had been taking $600 \mathrm{mg}$. of Tuinal nocte (quinalbarbitone sodium $300 \mathrm{mg}$. and amylobarbitone sodium $300 \mathrm{mg}$.). Over a period of three years after a hospital admission for treatment of a post-gastrectomy anaemia he had built up his consumption from 200 to $600 \mathrm{mg}$. of this drug. He reported that after several months at each dose level the drug "lost effect" and he had to increase the dose. When he tried to stop the drug he claimed that he did not sleep at all.

The recording procedure was as in experiment 1 , though no drug-free baseline nights were possible.

During the experiment the subject was asked to estimate his delay to sleep and total sleep time.

\section{Results}

While taking drugs this subject slept between 90 and $100 \%$ of the time available (Fig. 3). He regularly underestimated his total sleep and similarly overestimated his delay to sleep by a regular amount (Figs. 3 and 4). R.E.M. sleep was consistently at low normal levels (Fig. 5). At night 12 the drugs were stopped. R.E.M. sleep doubled in value and the first R.E.M. period was abnormally early. Total sleep time fell to $76 \%$ of that available and the number of awakenings increased. The delay to sleep was over 90 minutes. This disturbed night caused the subject to complain that he had not slept at all. Over the next three nights of withdrawal R.E.M. time remained increased, and the delay to sleep continued to be increased and total sleep time remained shortened. The subject continued to seriously underestimate the extent of his sleep and complained of fatigue and restlessness. His R.E.M. sleep was very active; not only were the periods of R.E.M. sleep longer but the movements themselves were more intense. The increase in " activity" has been shown to occur in withdrawal from other hypnotics (Evans and Lewis, 1968). Under these circumstances nightmares have been shown to occur (Oswald and Priest, 1965 ; Evans and Oswald, 1966).

At the subject's request the hypnotics were restarted at night 16. R.E.M. activity fell to its former level, and T.S.T. and delay to sleep returned to previous drug night values. 


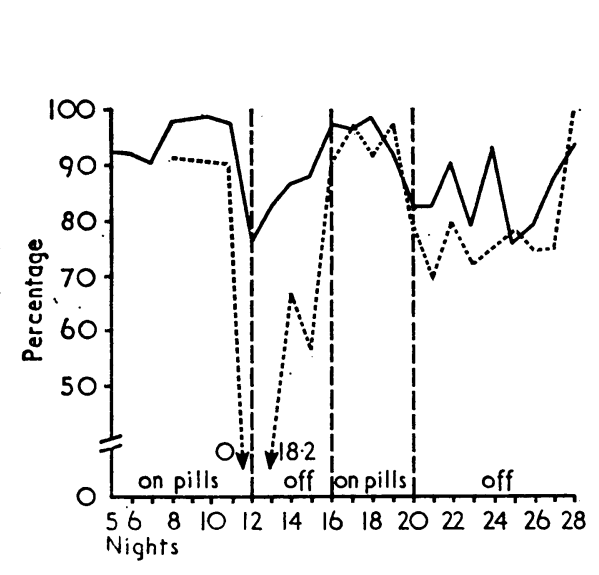

FIG. 3.-Percentage of sleep in time available.

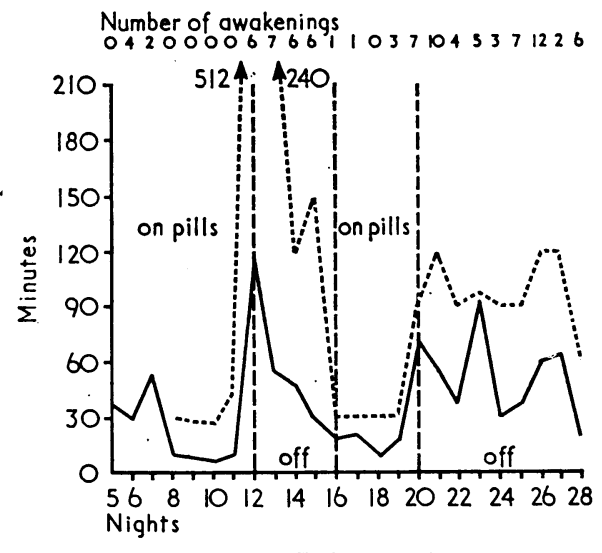

FIG. 4.-Delay to sleep.

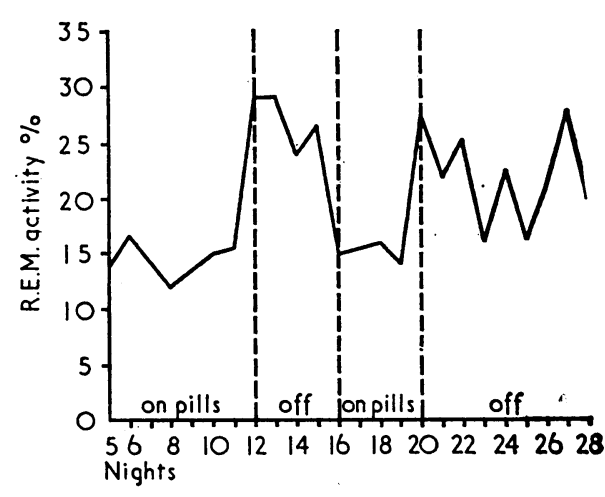

FIG. 5.-R.E.M. activity.
The subject's estimates returned to their previous reasonably accurate level.

Hypnotics were stopped again at night 20. The effects were sirailar to the previous withdrawal period and the irregularity $c t$ the onset of delay to sleep and total sleep time continued while the R.E.M. time remained raised in a fluctuant way.

\section{Discussion}

These experiments demonstrate the effects of barbiturates as well as some of the problems which accompany their use. A single tablet of sodium amylobarbitone promotes the early onset of sleep and enhances orthodox sleep while depressing R.E.M. sleep. The body responds immediately and attempts to restore the amount of R.E.M. sleep to normal values. After a week on the drugs the principal effects are in shortening the delay to sleep and promoting continuous sleep. However, even while the drug continues there are times when the delay to sleep increases; total sleep time falls and R.E.M. time is raised above the baseline. Though in experiment 1 this tendency was not severe, an "escape" phenomenon of this type may be the reason why patients increase the dose of hypnotics. Greenberg and Pearlman (1967) in their work on alcohol, which is very similar to barbiturates in its effect on sleep, also found that R.E.M. time could increase after a period of depression though the alcohol continued in full doses. It is possible that over a longer period total sleep time would fall and delay increase, as patients report.

Stopping the drug allows the overswing of R.E.M. sleep. This is experienced as an increase in activity by the patient, who may suffer from frightening dreams but frequently wakes up during R.E.M. periods. The R.E.M. activity, increase in the delay to sleep, and number of awakenings lead to a serious underestimate of the quality of sleep, and the sort of situation where the patient complains of total insomnia, while relatives or nurses differ in their opinion.

The temptation is to restart the tablets at the same or higher dose, and this, as seen in experiment 2 , puts the patient back to previous drug values. However, while the withdrawal effect of $200 \mathrm{mg}$. of sodium amylobarbitone takes almost two weeks to clear (Fig. 2), Oswald and Priest (1965) found that $600 \mathrm{mg}$. of sodium amylobarbitone took five weeks to subside. Thus by increasing the dose of hypnotics the patient is enhancing the duration of the withdrawal state. Although there is an end to these withdrawal effects the need to return to the drug is understandable.

If tolerance and withdrawal are the hallmarks of addiction, then only one tablet taken for a week could be seen to be addicting. However, the withdrawal is not severe. Serious withdrawal problems are not likely to occur until $800 \mathrm{mg}$. to $1 \mathrm{~g}$. of barbiturate is being regularly consumed. Although there is insufficient experimental evidence to suggest that all hypnotics act in this way, nitrazepam (Mogadon) depressed R.E.M. activity initially and produced a similar withdrawal state (Oswald and Priest, 1965). Kales et al. (1968) has shown that methyprylone (Noludar), glutethimide (Doriden), and methaqualone (Melsedin) also depress R.E.M. sleep initially and show a R.E.M. " overswing" withdrawal state. The literature confirms that almost all hypnotics, if taken in sufficient dose and for long enough, when stopped abruptly bring on a severe insomnia and a paranoid hallucinating state identical $\cdot$ with delirium tremens (de Clérambault, 1910 ; Hudson and Walker, 1962 ; James, 1963 ; Ewart and Priest, 1967). Recent work has shown that R.E.M. sleep is grossly increased in delirium owing to alcohol and barbiturate withdrawal (Gross et al., 1966; Greenberg and Pearlman, 1967 ; Evans and Lewis, 1968). Thus it seems likely that experiments will show that all hypnotics have these effects on R.E.M. sleep in some measure.

These experiments demonstrate that with barbiturates it is possible to promote sleep. However, there is some cost. In many ways hypnotics allow sleep to be "borrowed," and this must be paid back during withdrawal. It seems advisable to tail off hypnotics slowly, even from small doses, to minimize the withdrawal state, but it is also necessary to support the patient through the period of withdrawal, which is after all a limited event. It would perhaps be better to consider hypnotics as a course of treatment, with a beginning and a definite end, as soon as circumstances permit. It may also be more logical to prescribe intermittent courses of hypnotics so that withdrawal effects may be dissipated periodically and excessive build up of drugs prevented. It is an old criticism that doctors are good at starting and continuing treatment but not so good at stopping.

\section{REFERENCES}

Aserinsky, E., and Kleitman, N. (1953). Science, 118, 273. Aserinsky, E., and Kleitman, N. (1955). Ұ. appl. Physiol., 8, 1. Berger, R. J. (1961). Science, 134, 840.

Berger, R. J. (1961). Science, 134, 840.

de Clérambault, G. (1910). Ann. méd.-psychol., 10, 33. . physiol., 9 , 673 .

Evans, J. I., and Lewis, S. A. (1968). Proceedings of E.E.G. Society, In press.

Evans, J. I., and Oswald, I. (1966). Brit. F. Psychiat., 112, 401.

Ewart, R. B. L., and Priest, R. G. (1967). Brit. med.' F., 3, 92.

Goodenough, D. R., Shapiro, A., Holden, M., and Steinschriber, L. (1959). f. abnorm. soc. Psychol., 59, 295.

Greenberg, R., and Pearlman, C. (1967). Amer. f. Psychiat., 124, 133. Gross, M. M., et al. (1966). 7. nerv. ment. Dis., 142, 493.

Gross, M. M., et al. (1966). f. nerv. ment. Dis., 142, 493.

Hudson, H. S., and Walker, H. I. (1962). Amer.

Kales, A., et al. Presented at APSS meeting, March, 1968. Also personal communication.

Kessel, N. (1965). Brit. med. 7., 2, 1265, 1336.

Mendels, J., and Hawkins, D. R. (1967). Electroenceph. clin. Neurophysiol., 22, 556. Ministry of Health (1964). Recent N.H.S. Prescribing Trends. H.M.S.O.,
London.

Monroe, L. J., Rechtschaffen, A., Foulkes, D., and Jensen, J. (1965). f. Personal. Soc. Psychol., 2, 456.

Oswald, I., and Priest, R. G. (1965). Brit. med. F., 2, 1093.

Rechtschaffen, A., and Verdone, P. (1964). Percept. Mot. Skills, 1) 974

Snyder, F., Hobson, J. A., and Goldfrank, F. (1963). Science, 142, 1313 . Snyder, F., Hobson, J. A., Morrison, D. F., and Goldfrank, F. (1964).
f. appl. Physiol., 19, 417 . 